\title{
Price Responsiveness in District Heating: Single Houses and Residential Buildings-a Cross-Sectional Analysis
}

\author{
Stefan Hellmer \\ Industrial Management, Kristianstad University, 29188 Kristianstad, Sweden \\ Correspondence should be addressed to Stefan Hellmer; stefan.hellmer@hkr.se
}

Received 10 February 2013; Accepted 13 March 2013

Academic Editors: M. E. Kandil, M. Ransom, R. Wright, and J. Zarnikau

Copyright (C) 2013 Stefan Hellmer. This is an open access article distributed under the Creative Commons Attribution License, which permits unrestricted use, distribution, and reproduction in any medium, provided the original work is properly cited.

\begin{abstract}
Price responsiveness is argued to be one important factor determining the possibility for a natural monopoly such as a district heating company to exercise its monopoly power. Increased price responsiveness, measured, for example, by the own price elasticity, reduces monopoly power, as consumers increasingly reduce demand as a response to a price increase. However, consumers in single houses having individual metering have presumably higher price responsiveness compared to consumers in residential buildings using collective metering. One major question raised in this paper is thus whether single houses show larger price responsiveness compared to residential buildings. Using cross-sectional data for 187 networks in Sweden for the year 2007 indicates that even if single houses have higher price responsiveness, district heating reveals in general a very inelastic behavior.
\end{abstract}

\section{Introduction}

The Swedish energy markets were reregulated in 1996 and this had a significant influence on the market for district heating. The district heating market consists of many local vertically integrated natural monopolists that produce and distribute hot water to end consumers. Before the reregulation these companies were run as regulated municipal companies, regulated through the municipal nonprofit law. After the reregulation the district heating plants is expected to operate in a businesslike manner (Electricity Act, SFS 1997:857). The reregulation also led to substantial shifts in ownership with many district heating plants being sold to private actors or turned into joint-stock companies.

That district heating that constitutes a natural monopoly; that is, the average cost of production is decreasing as production increases up to at least the point where the entire demand is satisfied, has continuously been advocated by the Swedish Competition Authority [1] and the Swedish Energy Markets Inspectorate [2]. One company can consequently always provide the entire market at lower cost than two or more companies. However, just because a company that holds a natural monopoly position in a local market for district heating does not necessarily mean that the company can exercise a monopoly power, the market needs to lack close substitutes. District heating companies have the natural monopoly power for providing district heating but not in the entire heat market covering other alternative systems such as pellet burners and different kind of heat exchangers. Close substitutes combined with high (positive) cross-price elasticity and high own price elasticity reduce any natural monopoly power. Two important factors that influence the substitution flexibility comprise consequently the availability of alternative heat systems and the switching cost between the systems.

\section{Earlier Studies of Energy Market Elasticities}

Different reports and papers analyse the low price response in different energy markets such as the electricity market and the market for district heating. For example, both the Swedish Energy Markets Inspectorate [3] and the Swedish Competition Authority [1] emphasize the low price elasticity as an obstacle towards the ambition to increase the competitive pressure in these markets, as low elasticities increase the companies' market power. In addition, it is claimed by Carlson et al. [4], Ek and Söderholm [5], Wårell et al. [6], and Hellmer [7] that the low price elasticity is one major factor behind the lack of power shift from the producers 
to the consumers that was one of the ambitions within the reregulation in 1996.

There exists numerous studies on price elasticities for the electricity markets, but relatively few studies calculate and analyze price elasticities for heat markets in different countries and regions. Werner [8] uses data from 1970 to 2006 and estimates the price elasticities for district heating in Sweden to be $-0,35$; that is, a one percent price increase would result in a decreased consumption by 0,35 percent a relatively inelastic behaviour. Ghalwash [9] uses OLS and estimates different elasticities in a system of demand equations. Using Swedish data for 1980-2002 the price elasticity for district heating is calculated to be $-0,43$, and also that indicates a relatively inelastic behaviour. Brännlund et al. [10] use a similar method and come up with an estimate of the elasticity for district heating at $-0,31$. Leth-Petersen and Togeby [11] use Danish panel data for the years 1984-1995 and estimate the district heating price elasticity to be as low as $-0,02$. That the demand elasticity in Denmark that is so low is in fact to be expected. The Danish distinct heating market is regulated in such a way making it practically impossible for any consumer to switch to any other heating system [12]. Rehdanz [13] uses OLS on German socioeconomic panel data for 19982003 and calculates elasticity for heat demand to be between $-2,03$ and $-1,68$ for oil-based heating and between $-0,63$ and $-0,44$ for gas-based heating. These German elasticities are calculated for individual heating systems (as apart from district heating that is regarded as a collective system) and are therefore expected to show more price-sensitive behaviour. Haas and Biermayr [14] analyzed Austrian data from 1970 to 1995 and estimated the elasticity for heat demand to be -0,2, and Grohnheit and Klavs [15] used Cobb-Douglas and CES to estimate the price elasticity in Lithuania to be $-0,6$ for price increases and $-0,2$ for price decreases. These last two estimates indicate that consumers are more sensitive to price increases than price decreases; that is, in quantities consumers react more negatively when the price goes up than they react positively when the price goes down. A final analysis mentioned here is Kratena et al. [16] that used an econometric model with Austrian data for 1990-2006 and calculated the uncompensated elasticity to $-0,31$ and the compensated elasticity to $-0,26$. The compensated elasticity isolates the price elasticity under the assumption that the fall in real income created by the price increase is compensated for. For the sake of comparison, all other elasticities described in the text are uncompensated elasticities.

All of the mentioned elasticities are, with one exemption, different and show that the demand for heat is relatively inelastic. The study that deviates is the German study [13] that analyzed the demand situation for individual system and not a collective system that district heating represent. A small shortcoming of the described studies is that these do not estimate demand elasticities separately for different consumer groups such as, for example, residential buildings and small, detached, houses. Such a separation is perhaps difficult when dealing with time series data representing general yearly average values for prices and consumption. This study will use cross-sectional plant data and separate on two user categories, residential buildings and small houses.
In this way it will be possible to calculate and compare eventual differences in demand elasticities between these two consumer groups. Even if the study will exclude the price and usage of alternative heating systems such as heat pumps and pellets burners, it is expected that users in small houses will show higher price responsiveness in that this group have individual metering and easier accessibility to alternative systems to district heating.

\section{District Heating in Sweden a Short Description}

Over $50 \%$ of the total market for heat was provided through district heating in 2007 which is an increase from approximately $22 \%$ in 1978 . This increased share for district heating has taken place primarily on the expense on the use of oil and, since the beginning of the 90 s, also on the expense on the use of electrical heating, both the use of electrical panels and the use of water-based electrical heating [17].

The Swedish market for district heating is an unregulated market. Prior to the deregulation of the energy markets January 1, 1996, all district heating plants and distributing networks were owned and operated by each municipality. Then the district heating "companies" acted under the municipality law stating that no municipality owned company is allowed to make a profit, a type of price equal cost regulation with no specific target on district heating, just the ownership condition.

After the deregulation all companies engaged in the energy sector are supposed to operate in a business-like manner. There is one exception, energy transmission and distribution, which is regarded to be a natural monopoly and therefore have to be regulated. This means that the earlier municipality law is replaced by the electricity law with the above business-like condition, so after January 1, 1996, pricing of electricity, natural gas, and district heating is free. Many previously municipalities owned district heating plant and network have since then been sold to private operators such as FORTUM, E.ON, and Rindi as well as to the state owned Swedish company Vattenfall.

Even if the amount of district heating costumers living in single houses is by far the largest in comparison with other residential forms, district heating is not the most common used system in one- and two-family houses. If more than $70 \%$ of the area in residential buildings was heated with district heating in 2006 the same number for single households was limited to $10 \%$. Instead it is different sorts of and combinations of heat pumps that dominates the market for single houses. Table 1 shows the figures for 2003 and 2006.

Dominating systems for providing heat and hot water are thus heat pumps, electricity, and district heating. Also worth mentioning are wood based and pellet based burners (included in "others" in Table 1). District heating in Sweden has faced increasing competition from two obvious close substitutes; heat pumps and pellet burners.

Table 2 shows the price spread around the national median in SEK/MWh for the years 2001, 2004, 2007, and 2011. For every year there are more or less a $100 \%$ difference 
TABLE 1: Percentage share of heated area in single houses on heating system.

\begin{tabular}{lcc}
\hline Heating system & 2003 & 2006 \\
\hline Oil & $9 \%$ & $3 \%$ \\
District heating & $8 \%$ & $10 \%$ \\
Electricity & $29 \%$ & $31 \%$ \\
Heat pumps & $17 \%$ & $32 \%$ \\
Others & $37 \%$ & $24 \%$ \\
\hline
\end{tabular}

Source: Statistics Sweden.

TABLE 2: Median average and price spread in SEK/MWh, selected years.

\begin{tabular}{lcccc}
\hline Year & 2001 & 2004 & 2007 & 2011 \\
\hline Highest & 741 & 771 & 796 & 840 \\
Lowest & 338 & 371 & 405 & 441 \\
Median & 540 & 609 & 663 & 731 \\
\hline
\end{tabular}

Source: Avgiftsgruppen.

between the lowest and the highest prices in the Swedish market for district heating.

The highest price, $840 \mathrm{SEK} / \mathrm{MWh}$, is charged by the state owned company Vattenfall in Värmdö situated in east of Stockholm. The lowest price, $441 \mathrm{SEK} / \mathrm{MWh}$ is charged by the municipality owned company Luleå Energi in Luleå in the north of Sweden.

The data used in this study is collected from the Swedish Energy Market Inspectorate and Statistics Sweden. Individual plant data on production and deliveries to different consumer groups and prices comes from the inspectorate's yearly collection of information regarding Swedish district heating companies, and data on income in different regions comes from Statistics Sweden. The data includes information from 187 different district heating plants for 2007, the in 2011 latest year with complete data regarding all included variables. The material includes the price in $\mathrm{kWh}$, heat deliveries in GWh to residential buildings and to small houses, respectively, the number of connection points to each group for each individual network, 187 plants and networks. The average income in each region with a network is also included in order to control for eventual income effects measured in income elasticities.

\section{Elasticities}

The elasticities were calculated using OLS and the natural logarithm of the consumer price, average income, the number of connecting points for small houses, and residential buildings as independent variables. The natural logarithm of the heat delivery to respective user group was used as the dependent variables. The groups were analyzed separately as follows:

$$
\begin{aligned}
\ln \left(D_{i}\right)= & \ln (a)+e_{i} \ln (P)+E_{i} \ln (I)+\gamma \ln \left(C P_{i}\right) \\
& +\lambda \ln (\operatorname{ShRCP}),
\end{aligned}
$$

where $i=$ small houses or residential buildings. $D$ is heat deliveries in GWh to small houses or residential buildings,
$P$ is the consumer price in $\mathrm{SEK} / \mathrm{kWh}, C P$ is the number of connecting points to small houses or residential buildings, and ShRCP is the share of connecting points to residential buildings. By using the logarithmic values for all variables included all of the parameters to be estimated can be interpreted as elasticities.

The number of connecting points in each respective user group $\left(C P_{i}\right)$ is included in order to control for the size of demand with respect to the number of costumers. The share of connecting points for residential buildings (ShRCP) is included in both of the models for both categories: small houses and residential buildings. This in order to control for the network design linked to the relative number of residential buildings in a specific network. The parameter linked to this variable, $\lambda$, is expected to be relatively small but important since a small or large share of residential buildings in a network is assumed to have significant impact regarding the delivered heat in a network, but marginal changes in ShRCP is only expected to have marginal impact on the total amount of delivered heat in a network.

The price elasticity for small houses is generally expected to show higher price sensitivity compared to users in residential buildings. The first reason for this is that it can be assumed that users in small houses can more easily shift between heating systems compared to users in residential building. This is partly described in Hellmer [7] who, by defining involuntary lock-in, showed that users in residential building are to a larger extent locked in using district heating, while small houses to a larger extent can shift system as a response to higher district heating prices and changing price differences between different systems. The second reason is that small houses have individual metering. The owner of a small house can therefore more easily be informed of its own use of heat and can thus react more quickly to price changes. A residential building represents on the other hand only one connecting point with collective metering for the entire building usually with a flat rate for every apartment using most often the apartment size as an indicator for billing. This means that any individual apartment owner has limited information and possibility to make a significant change for the entire building. By using cross-sectional data it is reasonable to assume that any differences between the price elasticities capture the effect of individual metering. To catch the eventual substitution between different systems we would need additional data covering price and quantities of other competing heat systems and observations over more years to be able to use panel data.

The estimates of price elasticities are presented in Tables 3 and 4. These estimates indicate that the owner of a small house is twice as price sensitive as the users in a residential building. The price elasticity in small houses being $-0,48$, while the price elasticity for residential buildings was estimated to be $-0,25$. Even if the result indicates that small houses are more price sensitive compared to residential buildings, the general picture as described in earlier section, is that district heating shows a relatively inelastic behaviour.

The income elasticity is the same for both groups where both the estimates indicate a small but positive relationship between income and heat consumption. The estimates 
TABLE 3: Regression result small houses (elasticities).

\begin{tabular}{lccc}
\hline Variable & Coefficient & $t$-ratio & Significance \\
\hline Constant & $-1,34$ & $-0,27$ & 0,79 \\
Price & $-0,48$ & $-2,36$ & 0,02 \\
Income & 0,36 & 0,86 & 0,39 \\
$C P_{\text {small houses }}$ & 0,99 & 40,33 & 0,00 \\
ShRCP & 0,13 & 2,18 & 0,03 \\
\hline
\end{tabular}

$R$-square $=0,95$

Source: Own calculations.

TABLE 4: Regression result residential building (elasticities).

\begin{tabular}{lccc}
\hline Variable & Coefficient & $t$-ratio & Significance \\
\hline Constant & $-0,26$ & $-0,05$ & 0,96 \\
Price & $-0,25$ & $-1,20$ & 0,23 \\
Income & 0,37 & 0,86 & 0,39 \\
$C P_{\text {Residential Buildings }}$ & 1,12 & 38,82 & 0,00 \\
ShRCP & $-0,16$ & $-3,03$ & 0,00 \\
\hline$R$-square $=0,93$ & & &
\end{tabular}

Source: Own calculations.

regarding the number of connecting points are close to unity (1); that is, if the number of connecting points increases by one percent, the heat consumption will increase by one percent, a reasonable result.

The results of these regressions are not surprising or unexpected, the inelastic behaviour from earlier studies is further confirmed, and the differences in elasticities between two different user groups are added. The price elasticity for a user of heat living in s small house with individual metering is higher (more price sensitive) compared to heat users in a residential building. Since the material consists of crosssectional data, one important explanation for the difference in price response is the individual metering of small houses compared to the collective metering in residential buildings.

Further research will include the price of competing heat systems such as different heat pumps and pellet burners, both the price of the equipment and the usage cost. Further research should also include more years in order to obtain an eventual trend in price and cross-price elasticities as new, and improving alternatives to district heating evolves.

\section{Conflict of Interests}

The author of this paper has no direct or indirect financial relation of any kind to any of the commercial companies or authorities mentioned in the paper.

\section{References}

[1] Swedish Competition Authority, Competition in Sweden, 2007.

[2] Swedish Energy Markets Inspectorate, The Swedish Heat Market, 2007.

[3] Swedish Energy Markets Inspectorate, The Swedish Heat Market, 2010.
[4] A. Carlson, M. Lehmets, and S. Andersson, "Oportunity cost to district heating-a study of real costs in local heat markets," Fjärrsyn Rapport 7, 2008.

[5] K. Ek and P. Söderholm, "Households' switching behavior between electricity suppliers in Sweden," Utilities Policy, vol. 16, no. 4, pp. 254-261, 2008.

[6] L. Wårell, P. Söderholm, and J. Delsing, "District heating-a hot issue," Fjärrsyn Rapport 30, 2009.

[7] S. Hellmer, "Swtching Costs, Switching Benefit and Lockin Effects-The Reregulated Swedish Heat Market," Energy \& Environment, vol. 21, pp. 563-575, 2010.

[8] S. Werner, "Lower revenues from higher district heating prices?” Fjärrsyn Rapport 5, 2009.

[9] T. Ghalwash, "Energy taxes as a signaling device: an empirical analysis of consumer preferences," Energy Policy, vol. 35, no. 1, pp. 29-38, 2007.

[10] R. Brännlund, T. Ghalwash, and J. Nordström, "Increased energy efficiency and the rebound effect: effects on consumption and emissions," Energy Economics, vol. 29, no. 1, pp. 1-17, 2007.

[11] S. Leth-Petersen and M. Togeby, "Demand for space heating in apartment blocks: measuring effects of policy measures aiming at reducing energy consumption," Energy Economics, vol. 23, no. 4, pp. 387-403, 2001.

[12] B. Aronsson and S. Hellmer, "An International Comparison of District Heating Markets," Fjärrsyn Rapport 27, 2009.

[13] K. Rehdanz, "Determinants of residential space heating expenditures in Germany," Energy Economics, vol. 29, no. 2, pp. 167182, 2007.

[14] R. Haas and P. Biermayr, "The rebound effect for space heating empirical evidence from Austria," Energy Policy, vol. 28, no. 6-7, pp. 403-410, 2000.

[15] P. E. Grohnheit and G. Klavs, "Elastic electricity and heat demand in the balmorel model," Unpublished manuscript.

[16] K. Kratena, I. Meyer, and M. Wüger, "Modelling the energy demand of households in a combined top down/bottom up approach," WIFO Working Papers No. 321, 2008.

[17] S. Andersson and S. Werner, "District heating in Sweden," 2005, http://www.fvb.se/. 


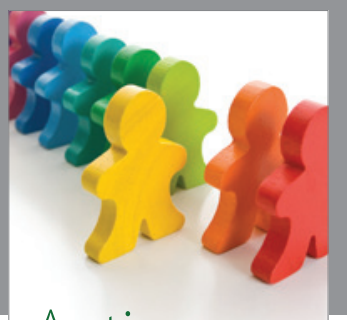

Autism

Research and Treatment
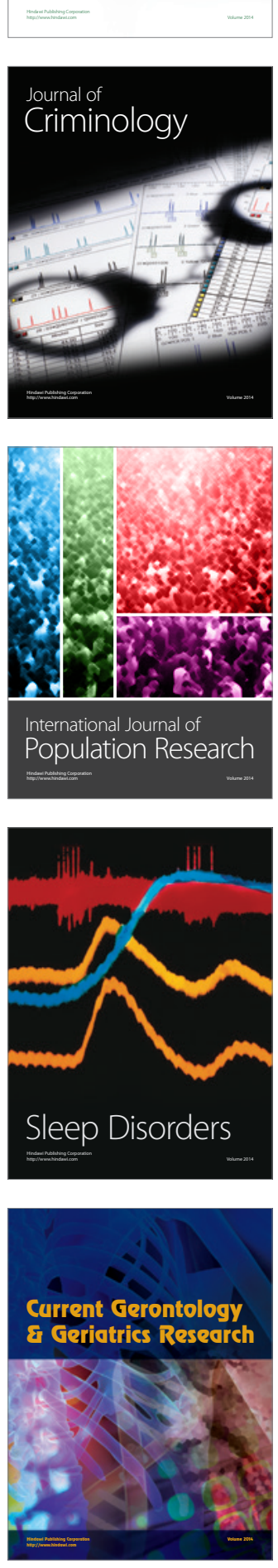
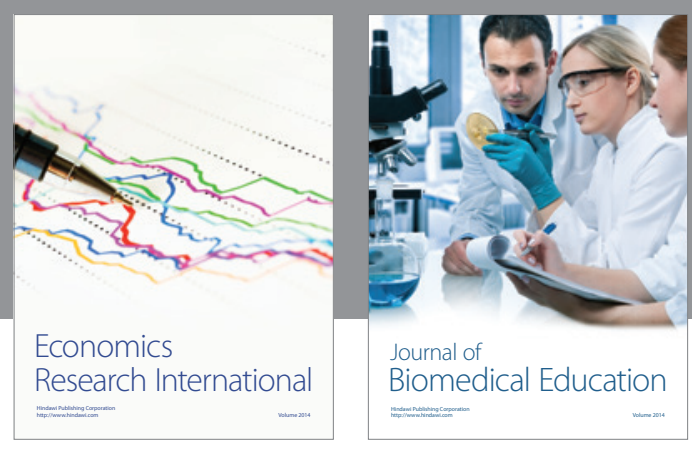

Journal of

Biomedical Education

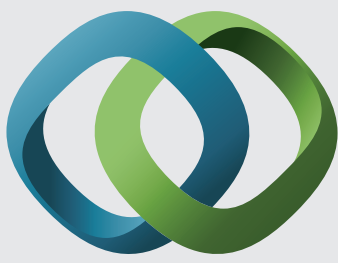

\section{Hindawi}

Submit your manuscripts at

http://www.hindawi.com
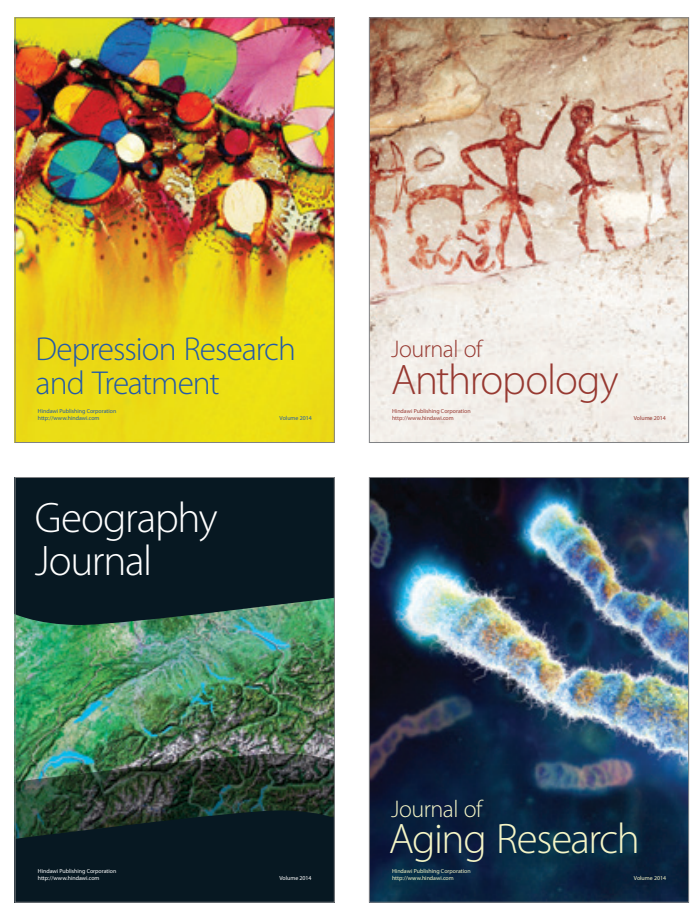

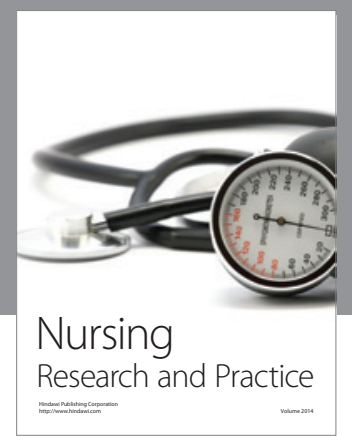

Nursing

Research and Practice

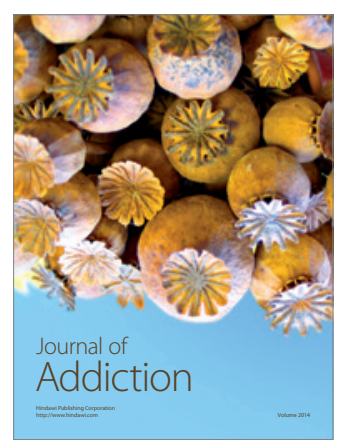

Child Development

Research

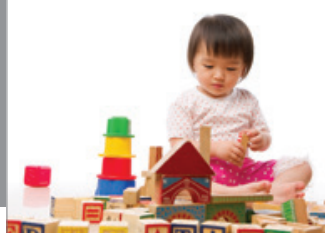

迥
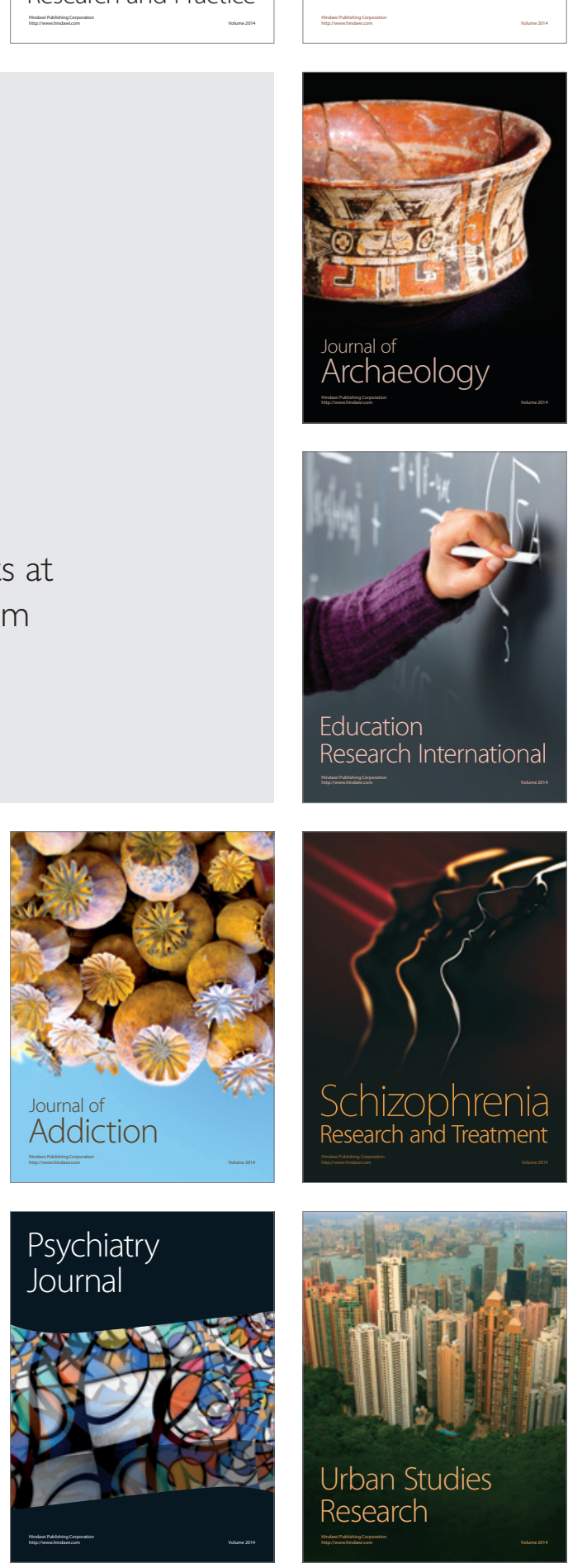